\title{
ULTRASONOGRAPHY-GUIDED FINE-NEEDLE ASPIRATION BIOPSIES OF THYROID NODULES: SINGLE CENTER EXPERIENCE
}

\author{
Salim Susuz1, Nur Kebapci1, Mahmut Kebapci2, Emine Dündar3, Aysen Akalın1, Belgin Efe1 \\ Eskisehir Osmangazi University, Department of Endocrinology1, Radiology2 and Pathology3
}

\section{Objectives:}

Methods:

\section{Results:}

Conclusions:

References:
In the present study, we aimed to investigate the efficiency of ultrasound-guided fine-needle aspiration biopsy in our clinic.

Totally 701 patients followed at Eskisehir Osmangazi University Faculty of Medicine Department of Endocrinology with nodular thyroid disorder were included in this study during January 2000 and January 2011. Ultrasound-guided thyroid fine-needle aspiration biopsy was performed in these 701 cases at interventional radiology department. Throid nodules were evaluated in terms of size, echo quality, peripheral halo and calcification. The biggest diameter was determined measuring three dimensions of nodule. If multiple nodules were found in a patient, TFNAB was performed from the biggest dominant nodule.

The result of US-TFNAB was insufficient in $11.7 \%$ of patients. US-TFNAB was reported as benign in $79.3 \%$ of patients, suspected malignant in $4 \%$, malignant in $3.9 \%$ and suspected follicular neoplasm in $1.1 \%$. When suspected follicular neoplasm and suspected malignancy cases were included into malignant group, the malignancy ratio based on US-TFNAB was $9 \% .146$ of 701 cases were operated $(20.8 \%), 19$ cases $(2.7 \%)$ didn't accept the surgery. According to histopathology results of operated patients, 66 patient were malignant and 80 were benign . No significant gender difference was determined for benign or malignant histopathology results $(p>0.05)$.

When all cases with suspected follicular neoplasm, suspected Hurthle-cell neoplasm, suspected malignancy and suspected papillary carcinoma were included into malignancy group, the sensitivity was $79.4 \%$, specificity was $83.8 \%$, overall accuracy rate was $81.8 \%$, positive predictive value was $80.6 \%$ and negative predictive value was $82.7 \%$.

A clinical assessment performed an experienced clinician, US-guided TFNAB performed by an experienced radiologist and pathologic evaluation by a cytopathologist is a team work which will achieve success to identification of malignant thyroid nodules in all patients with nodular thyroid. 